\title{
THE STATE OF RESEARCH ON INTERNAL WAR
}

\author{
Jesse Orlansky
}

August 1970

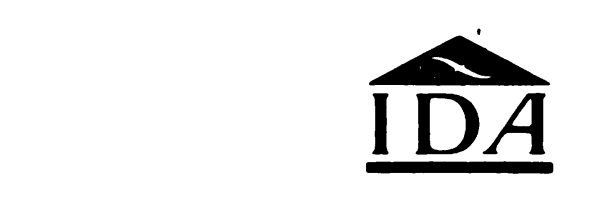

INSTITUTE FOR DEFENSE ANALYSES

SCIENCE AND TECHNOLOGY DIVISION

400 Army-Navy Drive, Arlington, Virginia 22202

Contract DAHC15 $67 \mathrm{C} 0011$

ARPA Assignment 20 